\title{
AGE-RELATED DISTURBANCES IN DNA (HYDROXY)METHYLATION IN APP/PS1 MICE
}

Brain aging has been associated with aberrant DNA methylation patterns, and changes in the levels of DNA methylation and associated markers have been observed in the brains of Alzheimer's disease (AD) patients. DNA hydroxymethylation, however, has been sparsely investigated in aging and AD. We have previously reported robust decreases in 5-methylcytosine (5-mC) and 5-hydroxymethylcytosine (5-hmC) in the hippocampus of AD patients compared to non-demented controls. In the present study, we investigated 3- and 9-month-old APPswe/PS1 $1 \mathrm{E} 9$ transgenic and wild-type mice for possible age-related alterations in 5-mC and 5-hmC levels in three hippocampal sub-regions using quantitative immunohistochemistry. While age-related increases in levels of both 5-mC and 5-hmC were found in wild-type mice, APPswe/PS1 $\mathrm{E} 9$ mice showed decreased levels of $5-\mathrm{mC}$ at 9 months of age and no age-related changes in 5-hmC throughout the hippocampus. Altogether, these findings suggest that aberrant amyloid processing impact on the balance between DNA methylation and hydroxymethylation in the hippocampus during aging in mice.

Keywords

Aging • Alzheimer's Disease $\cdot$ APPswe/PS1 $\triangle E 9 \cdot$ Epigenetics $•$ DNA methylation $•$ DNA hy-droxymethylation

\section{Abbreviations}

5-hmC, 5-hydroxymethylcytosine; 5-mC, 5-methylcytosine; $A \beta$, amyloid- $\beta$; $A D$, Alzheimer's disease; APP, amyloid precursor protein; $C A$, cornu ammonis; $D A B$, 3,3'-diaminobenzidine tetrahydrochloride; $D G$, dentate gyrus; DNMT, DNA methyltransferase; HDAC, histone deacetylase; HDACi, HDAC inhibitors; IR, immunoreactivity; MBD, methylbinding protein; $\mathrm{MeCP}$, methyl-CpG binding protein; PS, presenilin; SPF, specified pathogen free; TET, ten-eleven translocation; WT, wildtype

\section{Introduction}

Alzheimer's disease $(A D)$ is the most common form of dementia and its neuropathology is associated with altered gene expression, in a hippocampal subregion-specific manner [1,2]. Mutations in the genes encoding amyloid precursor protein (APP) and presenilin (PS) 1 have been identified in autosomal dominant cases of $A D$ and are known to affect brain function by altering APP processing during aging, producing toxic amyloid beta $(A \beta)$ protein species $[3,4]$.

Accumulating evidence suggests that epigenetic regulation of gene expression is critically involved in the pathophysiology of $A D[5,6]$. Altered global levels of the DNA methylation marker 5-methylcytosine (5-mC) and changes in gene-specific methylation profiles have been observed in post-mortem brain material of $A D$ patients, in peripheral lymphocytes of $A D$ patients and also in animal and cell culture models of AD neuropathology
Leonidas Chouliaras ${ }^{1,2 *}$,

Roy Lardenoije ${ }^{1}$,

Gunter Kenis',

Diego Mastroeni ${ }^{1,2}$,

Patrick R. Hof ${ }^{3}$,

Jim van $\mathrm{Os}^{1,5}$,

Harry W.M. Steinbusch ${ }^{1}$

Fred W. van Leeuwen',

Bart P.F. Rutten ${ }^{1, *}$,

Daniel L.A. van den Hove ${ }^{1,6, \#}$

School for Mental Health and Neuroscience (MHeNS), Department of Psychiatry and Neuropsychology, Faculty of Health, Medicine and Life Sciences, European Graduate School of Neuroscience (EURON), Maastricht University Medical Centre, Maastricht, The Netherlands.

${ }^{2}$ Current: Department of Psychiatry, University of Cambridge, Cambridge UK

${ }^{3}$ ASU-Banner Neurodegenerative Disease Research Center, Biodesign Institute and School of Life Sciences, Arizona State University, Tempe, AZ, USA; Banner Sun Health Research Institute, Sun City, AZ, USA

${ }^{4}$ Fishberg Department of Neuroscience and Friedman Brain Institute, Mount Sinai School of Medicine, New York, USA

${ }^{5}$ Department of Psychiatry, Brain Centre Rudolf Magnus, University Medical Centre Utrecht, Utrecht, the Netherlands.

${ }^{6}$ Department of Psychiatry, Psychosomatics and Psychotherapy, University of Würzburg, Würzburg, Germany

"These authors contributed equally to this work

Received 11 April 2018

accepted 26 November 2018

[7-14]. Further implication of epigenetic dysregulation in $A D$ is supported by studies showing that treatment with HDAC inhibitors (HDACi), drugs that target the epigenetic machinery, improve behavioral outcomes in transgenic mouse models of $A D[15,16]$.

The oxidized form of $5-\mathrm{mC}$, 5-hydroxymethylcytosine (5-hmC), has also been identified as an epigenetic regulator, that is particularly abundant in the brain $[17,18]$. Additionally, oxidation of 5-mC is thought to be the initial step of an active DNA demethylation pathway $[19,20]$. To date, still little is known about the role of DNA hydroxymethylation in $A D$ [21]. Studies on the mouse hippocampus and cerebellum reported dynamic changes of 5-hmC during neurodevelopment and aging, such as an age-associated increase of hydroxymethylation of genes related to 
amyloid processing $[22,23]$. Interestingly, a genetic association between $A D$ and one of the enzymes that catalyze the $5-\mathrm{mC}$ to $5-\mathrm{hmC}$ conversion, ten-eleven translocation (TET) 1, has been reported [24], suggesting that the conversion from $5-\mathrm{mC}$ to $5-\mathrm{hmC}$ might be particularly important in AD. Furthermore, we have reported a robust reduction of the DNA methylation marker 5-mC and the DNA methylation marker 5-hmC in the hippocampus of $A D$ patients compared to matched controls, as well as an AD-associated decrease in 5 -hmC in the hippocampus of a monozygotic twin pair discordant for AD [25]. Recently, the first epigenome-wide analyses of $5-\mathrm{hmC}$ in relation to $A D$ was published, identifying numerous sites with altered hydroxymethylation [26].

Aging is the most important risk factor for $A D$ and age-related changes in epigenetic mechanisms in $A D$-vulnerable brain regions may thus be involved in setting the stage for the development of AD [27-29]. We have previously shown in large cohorts of wildtype (WT) mice that aging is associated with increased levels of 5-mC, as well as increased levels of 5 -hmC in the hippocampus and cerebellum [30-32]. However, there is no conclusive evidence on whether age-related aberrations in APP and A $\beta$ processing impact on the balance between $5 \mathrm{mC}$ and $5 \mathrm{hmC}$ in the brain. As such, it remains unknown whether the reports of global epigenetic changes in the $A D$ brain are closely associated with aberrant amyloid processing.

Based on the postulated misbalance between DNA methylation and DNA hydroxymethylation in the pathophysiology of $A D$ [33] and our findings in the hippocampus of $A D$ patients and controls [25], the aim of the current study was to investigate agerelated changes in hippocampal levels of DNA methylation and DNA hydroxymethylation, in a mouse model carrying familial mutations of $\mathrm{AD}$. For that purpose, 5-mC and 5-hmC immunoreactivity (IR) was assessed in three hippocampal subregions, the dentate gyrus (DG), cornu ammonis (CA) 3, and CA1-2, of 3- and 9-month-old WT mice and transgenic APPswe/PS1 $\triangle E 9$ mice. The transgenic APPswe/ PS1 $1 \mathrm{E} 9$ mice that were used overexpress APP but overall are a relatively low expresser of APP compared to other transgenic mice models of AD neuropathology such as the PDAPP and the $\operatorname{Tg} 2576$ [34]. The APPswe/PS1 $\triangle E 9$ mice used develop AD-like amyloid pathology by 4 months of age due to a high ratio of $A \beta 42 /$ $A \beta 40$ ratio due to presence of the Presenilin mutation $[35,36]$. Hippocampal amyloid plaque loads were analyzed in these mice to verify $A \beta$ deposition.

\section{Materials and methods}

\subsection{Animals}

The present study used 11 male WT C57Bl6J and 9 male transgenic APPswe/PS1 $\triangle \mathrm{E} 9$ mice on a C57Bl6 background. The double transgenic APPswe/PS1 $1 \mathrm{E} 9$ line 85 , originally described by [37], carries a co-integrate of 1) chimeric mouse/human APP695 carrying the Swedish mutation (K594M/N595L) and 2) human PS1 with deletion of exon 9 [35], each under control of a mouse prion protein promoter. Line 85 was back-crossed to a C57Bl6 background for more than seven generations. PCR amplification of genomic DNA, isolated from the mouse tails, was performed in order to determine the presence of the APP and PS1 mutations and verify the genotype of the mice used in the present study as described previously (van Tijn et al., 2012). All mice were housed in groups of two with ad libitum access to food and water kept on a 12/12-hour light:dark circle, and under standard temperature, humidity and specified pathogen free (SPF) conditions. All experiments were approved by the Animals Ethics Board of Maastricht University.

\subsection{Experimental Design}

Mice were sacrificed at ages of 3 and 9 months for immunohistochemical analysis. Thus, 4 experimental groups were generated based on age and genotype: 1) 3-month-old-WT mice $(n=5), 2)$ 9-month-old WT mice $(n=6), 3)$ 3-month-old APPswe/PS1 $\triangle$ E9 mice $(n=4)$, and 4) 9-month-old APPswe/PS1 $\triangle E 9$ mice $(n=5)$.

\subsection{Tissue processing}

The mice were anaesthetized and transcardially perfused with tyrode solution and fixative solution (4\% paraformaldehyde, $0.9 \% \mathrm{NaCl}$ $1 \%$ acetic acid). Subsequently, the brains were removed and stored in a $1 \%$ sodium azide TBS solution (at $4^{\circ} \mathrm{C}$ ). They were then embedded in $10 \%$ gelatin and cut serially in $50 \mu \mathrm{m}$-thick freefloating sagittal sections using a vibratome (VT 1200S, Leica, Wetzlar, Germany), yielding 10 sub-series of every 10th section. These were stored again in $1 \%$ sodium azide TBS solution at $4^{\circ} \mathrm{C}$ until further histological processing.

\subsection{Immunohistochemical detection of 5-mC and 5-hmC}

For each immunohistochemical procedure, a series of sections was stained using standard immunohistochemical protocols as previously described [30,31,38]. Mouse monoclonal anti-5-mC (dilution 1:500, Genway Biotech, San Diego, CA, USA) was used as a primary antibody for 5-mC, and a biotinylated donkey anti-mouse (dilution 1:200; Jackson Westgrove, PA, USA) as the secondary antibody. For the detection of 5-hmC, a rabbit polyclonal anti-5hmC antiserum (dilution 1:25,000; Active Motif, Rixensart, Belgium) was used as a primary antibody and a biotinylated donkey anti-rabbit (dilution 1:200; Jackson Westgrove, PA, USA) as the secondary antibody. For each primary antibody, the sections were processed as a single batch to avoid differences in staining intensities between batches. The specificity of the commercially available primary antibodies has been confirmed in our previous work $[25,39]$

\subsection{Semi-quantitative analysis of 5-mC and 5-hmC IR}

Mean intensity and surface area of 5-mC and 5 -hmC IR were analyzed. For each of the 2 markers, 2 images from the CA1-2 region, 2 images from the CA3 pyramidal layer and 4 images from the granule cell layer of the DG were taken (Figure 1) at 4 different lateral levels $(2.525 \mathrm{~mm}, 1.95 \mathrm{~mm}, 1.35 \mathrm{~mm}$ and $0.675 \mathrm{~mm}$ according to the Allen Brain Atlas (http://mouse.brain-map.org/), using a $40 \mathrm{x}$ objective. Thus, a total of 32 images were taken for every animal for each marker, with a digital camera (F-view; Olympus, Tokyo, Japan) connected to an Olympus AX70 brightfield microscope (AnalySIS; Imaging System, Münster, Germany). Mean intensities and surface area measurements of each image were 
obtained using the ImageJ software program (version 1.42q, Wayne Rasband, National Institutes of Health, Bestheda, Maryland, USA), after delineating the regions of interest and correcting for background variation by setting minimum thresholds as previously described in detail $[30,31,38]$. For statistical analyses the raw data derived from each image (intensity and surface area) were averaged for each animal. Surface area measurements might be affected by volume changes and could be corrected for that [38]. However, in the present study no significant hippocampal volume changes were detected (data not shown) and thus corrections for volumes were not performed. While the present analysis focused on semiquantitative analysis of global 5-mC and 5-hmC distribution, previously published work from our group has shown quantitative validation of immunohistochemical findings using dot-blots [39].

\subsection{Hippocampal A $\beta$ plaque load IR} Hippocampal amyloid plaque loads were determined with a triple fluorescence immunohistochemical analysis in a series of sections from the same mice used for the $5-\mathrm{mC}$ and $5-\mathrm{hmC}$ staining. An antibody against the $\mathrm{N}$-terminal of $A \beta$ (Amyloid $\beta[\mathrm{N}$ ] IBL international, Hamburg, Germany) was used to stain all $A \beta$, thioflavin $S$ (Sigma Aldrich, Zwijndrecht, The Netherlands) to stain highly dense-core plaques, and 4',6-diamidino-2phenylindole dihydrochloride (DAPl; Sigma Aldrich, Zwijndrecht, The Netherlands) was used as a counterstain. Briefly, antigen retrieval was performed with $10 \mathrm{mM}$ citric buffer $\mathrm{pH} 6.0$ at $95^{\circ} \mathrm{C}$. Then, the sections were rinsed with TBS and TBS-T, incubated with $\mathrm{H}_{2} \mathrm{O}_{2}$ to quench endogenous peroxidase, washed again with TBS and TBS-T, and blocked with 3\% NDS in TBS-T before overnight incubation with the primary antibody (diluted $1: 1000$ in $0.3 \%$ NDS). The next day, the sections were rinsed again with TBS and TBS-T, incubated with the secondary antibody (donkey anti-mouse Alexa 594 Invitrogen, Grand Island, NY, USA), rinsed again with TBS and TBS-T, incubated with thioflavin $S(0.0075 \%)$ for 10 minutes, and then rinsed for 5 minutes in $70 \%$ ethanol. Subsequently, the sections were washed

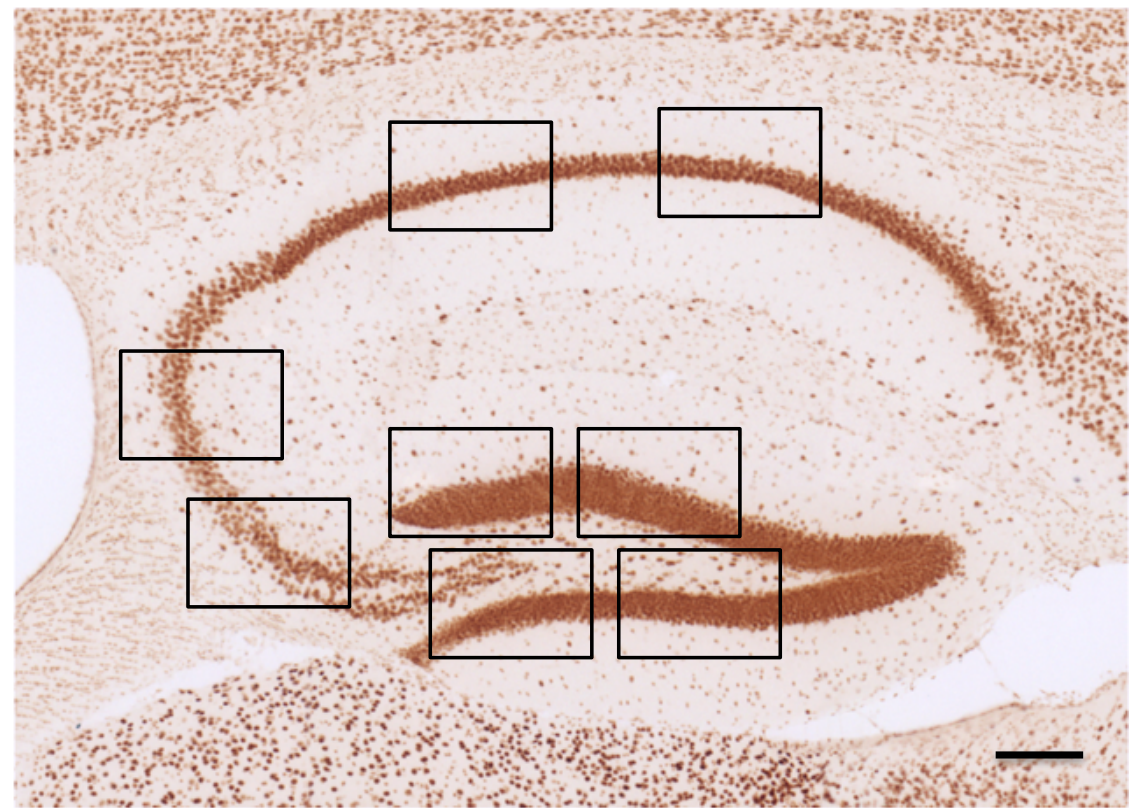

Figure 1. Hippocampal 5-hydroxymethylcytosine $(5-\mathrm{hmC})$ immunoreactivity (IR). Representative photomicrograph of a hippocampal section stained for 5 -hmC (lateral level $1.35 \mathrm{~mm}$ ). The black boxes indicate where the high-magnification photomicrographs were taken for both the 5 -hmC and the 5-methylcytosine (5-mC) analysis. A total of 32 photomicrographs per animal (4 photomicrographs in the dentate gyrus, 2 in the cornu ammonis [CA] 3, and 2 in the CA1-2 regions, at 4 different lateral levels) were taken for each staining (see text for more details). Scale bar $=200 \mu \mathrm{m}$.

again with TBS and TBS-T and counterstained with DAPI. The sections were then mounted on gelatin-coated microscope glasses, taken through Sudan black (Sigma Aldrich, St Louis, $\mathrm{MO}$, USA) to reduce autofluorescence, and coverslipped using $80 \%$ glycerol in TBS.

\subsection{Analysis of Hippocampal A plaque load densities}

All measurements were performed using a modified BX50 bright field microscope (Olympus, Tokyo, Japan), Olympus UPlanApo objectives (Olympus), a three-axis highaccuracy computer-controlled stepping motor specimen stage for automatic sampling (4x4 Grid Encoded Stage; Ludl Electronics, Hawthorne, NY, USA), a linear z-axis position encoder (Ludl), a MBF-CX9000 CCD color camera $(1200 \times 1800$ pixels; CX9000; MBF Bioscience, Williston, VT, USA), and controlling software (Stereo Investigator, MBF Bioscience). Plaque density analysis was performed in all the hippocampal sections stained for $A \beta$. Delineations of the total hippocampus and the cell layers of the $D G$, the $C A 3$ and the $C A 1-2$ were performed using the 20x objective. Within the delineated areas, the plaque area was measured with the Area Fraction Fractionator probe of the Stereo Investigator software using a 40x objective (oil, $N A=1.00$ ). Thioflavin $S$ staining indicated the presence of dense-core plaques, while antibody $A \beta[N]$ could demonstrate the less fibrillar plaque load. The plaque area was compared to the total hippocampal area of that respective section to obtain an estimate of the plaque load (Supplementary Figure 1).

\subsection{Statistical Analysis}

All data are presented as mean and standard error of the mean (SEM). The general linear model univariate analysis of variance (GLM) was used for comparisons between groups, accounting for the main and interactive effects of age and genotype. Statistical significance was set at $a=0.05$ and corrected total degrees of freedom (df)=19 for all main comparisons. Pairwise comparisons were performed with a Bonferroni post-hoc test. In the absence of a significant interaction, main effects of age were analyzed through an additional stratified 
$5-m C$

3M-WT

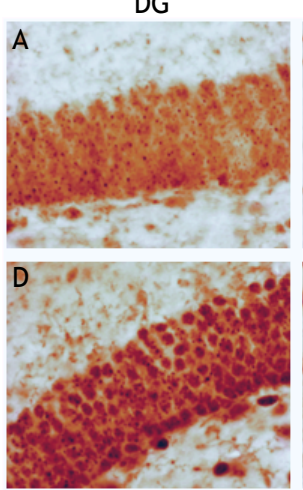

9M-WT
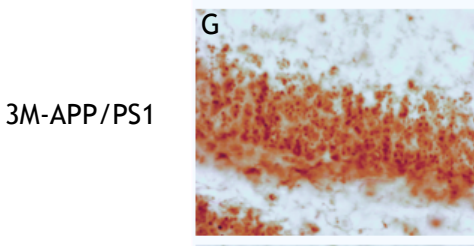

J

9M-APP/PS1

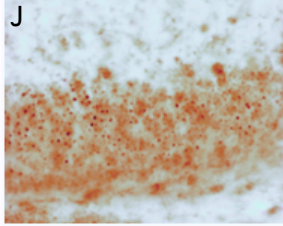

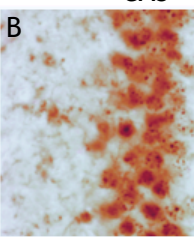

CA3
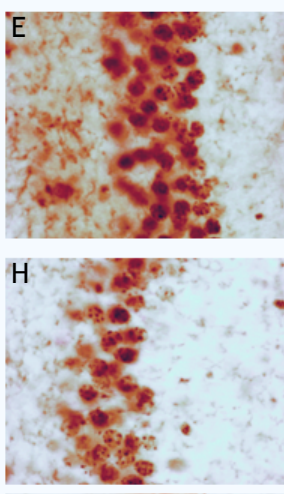

K

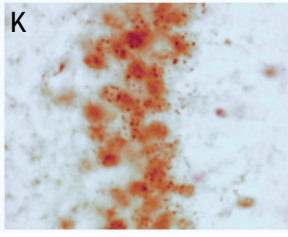

CA1-2
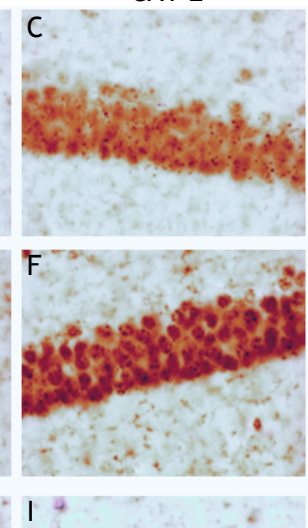

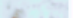

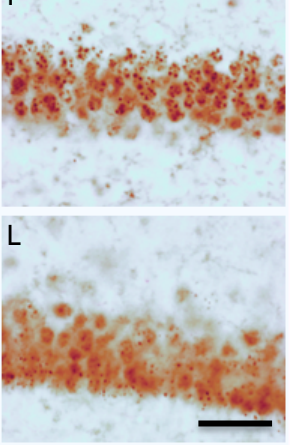

Figure 2. Representative photomicrographs of 5-methylcytosine (5-mC) immunoreactivity (IR). High-magnification representative fields of the hippocampal dentate gyrus (DG), cornu ammonis (CA) 3, and CA1-2 regions are shown. A-C represent a 3-month-old wild-type (WT) mouse, D-F represent a 9-month-old WT mouse. G-I, represent a 3-month-old APPswe/PS1 $\triangle \mathrm{E} 9$ mouse, and J-L a 9-month-old APPswe/PS1 $\triangle \mathrm{E} 9$ mouse. Note that an increase in 5-mC IR is observed from 3 to 9 months in WT mice, while a loss of 5-mC IR is observed in from 3 to 9 months in APPswe/PS1 $\triangle \mathrm{E} 9$ mice in all three hippocampal subregions. The photomicrographs were taken with a $40 \mathrm{x}$ objective. Scale bar $=50 \mu \mathrm{m}$.

analysis per genotype, to assess whether overall effects of age were more pronounced in a particular genotype group (corrected total $\mathrm{df}=10$ for WT groups and $\mathrm{df}=8$ for APPswe/ $\mathrm{PS} 1 \triangle \mathrm{E} 9)$. Correlation analyses between 5-mC and 5-hmC intensity measurements were carried out by calculating the Pearson's correlation coefficient $\left(r_{p}\right)$. All statistical calculations were performed using the Statistical Package for the Social Sciences, (SPSS 17, SPSS Inc., Chicago, IL, USA). Graphs were built in GraphPad Prism (Version 4, GraphPad Software, San Diego, USA).

\section{Results}

3.1 Qualitative analysis of 5-mC and 5-hmC IR

Nuclear IR of both 5-mC and 5-hmC was observed in the hippocampal subregions (Figures 2 and 3). 5-mC IR consisted mainly of compact condensations, while 5 -hmC IR was spread throughout the nucleus. Qualitative microscopic inspection indicated marked increases of both 5-mC and 5-hmC IR in all three hippocampal subregions of 9-month-old as compared to 3-month-old WT mice (Figures $2 \mathrm{~A}-\mathrm{F}$ and $3 \mathrm{~A}-\mathrm{F})$. In contrast, an age-related decrease of 5-mC IR (Figure 2G-L) was observed in the 9-month-old as compared to 3-monthold APPswe/PS1 1 E9, while no apparent differences in 5-hmC IR were observed in these same mice (Figure 3G-L).

\subsection{5-mC intensity}

GLM revealed a main effect of genotype in the DG $(p<0.001, F=22.2)$ and CA1-2 $(p=0.008$, $F=8.9$ ) regions, and a main effect of age in the
DG $(p=0.02, F=6.7$; Figure 4A-C). Furthermore, statistically significant age $x$ genotype interactions were observed in all hippocampal subregions $(p=0.001, F=17.3$ for $D G, p=0.002$, $F=14.2$ for $C A 3$, and $p=0.004, F=11.1$ for $C A 1$ 2; Figure $4 A-C)$. Pairwise Bonferroni post-hoc comparisons showed that age was associated with a significant increase in the intensity of $5-\mathrm{mC}$ IR in the DG $(+8.6 \%, \mathrm{p}=0.001)$ and the CA3 (+6.5\%, $p=0.044)$ regions of WT mice. Moreover, Bonferroni post-hoc comparisons revealed a decrease of 5-mC IR intensity in the 9-month-old APPswe/PS1 $\triangle$ E9 mice compared to 9-month-old WT mice in all hippocampal subregions $(-11.3 \%, p<0.001$ for DG; $-9.1 \%, p$ $=0.004$ for CA3; and $-10.8 \%, p=0.001$ for CA 1 2). Thus, age was associated with significantly higher levels of 5-mC IR in WT mice, whereas the APPswe/PS1 1 E9 genotype with lower levels of 5-mC IR in 9-month-old mice.

\subsection{5-mC surface area}

GLM for surface area measurements of 5-mC IR showed a significant age $x$ genotype interaction in the $D G(p=0.048, F=4.6)$ (Figure $4 D)$, but not in CA3 $(p=0.079)$ or CA1-2 $(p=$ 0.104). Pairwise post-hoc comparisons using the Bonferroni correction showed that the observed changes were not specific for any individual experimental groups.

\subsection{5-hmC intensity}

GLM revealed non-significant effects for the main effect of age in the DG $(p=0.053)$ and the CA3 $(p=0.099)$ subregions, and no effect in the CA1-2 region $(p=0.149)$. Stratified analyses per genotype showed an increase of mean intensity of 5-hmC IR associated with aging from 3- to 9-month-old mice in all hippocampal subregions $(p=0.022, F=7.6$ for $D G, p=0.016$, $\mathrm{F}=8.64$ for $\mathrm{CA} 3$, and $\mathrm{p}=0.044, \mathrm{~F}=5.5$ for $\mathrm{CA} 1-2$ ) in the WT mice, but not in the APPswe/PS1 $\triangle E 9$ mice ( $p=0.565$ for $D G, p=0.688$ for $C A 3$, and $p$ $=0.726$ for $C A 1-2)$ (Figure $5 A-C$ ).

\subsection{5-hmC surface area}

GLM revealed non-significant trends for increased 5 -hmC surface area IR by age in the DG $(p=0.074)$ and the CA3 $(p=0.054)$ subregions, and no effect in CA1-2 ( $p=0.249$; Figure 5D-F). 


\subsection{5-mC and 5-hmC correlation}

Correlation analyses between $5-\mathrm{mC}$ and 5-hmC IR revealed non significant positive correlations between 5-mC and 5-hmC IR in the DG $\left(r_{p}=\right.$ $0.542, p=0.085)$ and the CA3 $\left(r_{p}=0.576, p=\right.$ 0.064 ) regions of WT mice, and no effects in the CA1-2 $\left(r_{p}=0.211, p=0.534\right)$. No correlations between $5-\mathrm{mC}$ and $5-\mathrm{hmC}$ IR were observed in the APPswe/PS1 $\triangle E 9$ transgenic mice (Figure $6 A-F)$.

\subsection{Hippocampal $A \beta$ plaque load densities}

Amyloid plaque analysis demonstrated an agedependent deposition from 3- to 9-month old mice (Supplementary Figure 1).

\section{Discussion}

Qualitative and quantitative assessment of the various hippocampal subregions revealed that aging in WT mice was associated with increased levels of 5-mC and 5-hmC. APPswe/ PS1 $1 \mathrm{E} 9$ mice showed, however, lower levels of 5-mC IR at 9 months of age and no significant alterations in 5-hmC levels. Altogether, these findings indicate that mutations in APP and/ or PS1 impact on the balance between DNA methylation and hydroxymethylation in the aging hippocampus.

\subsection{Age-related increase of hippocampal 5-mC and 5-hmC IR in WT mice}

In the present study, 5-mC IR was increased in 9-month-old compared to 3-month-old WT mice. As the anti-5-mC antibody detects CpGrich loci with higher sensitivity, the observed increase of 5-mC IR likely reflects increased methylation of $\mathrm{CpG}$ islands [31]. These findings are in agreement with studies reporting that aging is associated with increases in global DNA methylation in brains of rodents $[40,41]$, as well as hypermethylation of $\mathrm{CpG}$ islands and loss of methylation of loci outside CpG islands $[27,42,43]$. Our current findings of increased 5-mC IR from 3- to 9-month-old WT mice are in accordance with our earlier findings of age-associated increases in levels of 5-mC [31] and DNA methylation-associated markers, like Dnmt3a and HDAC2 in C57BI6

Figure 3. L. Chouliaras et. al.

$5-\mathrm{hmC}$

DG
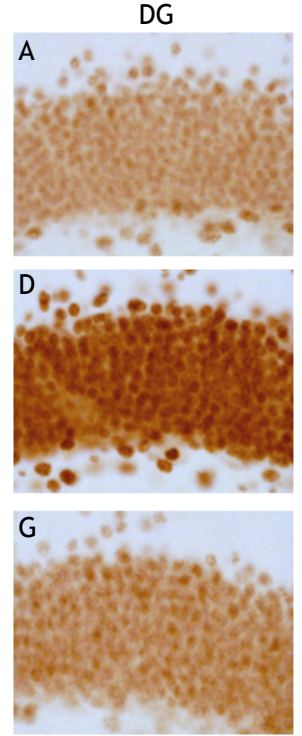

J

9M-APP/PS1

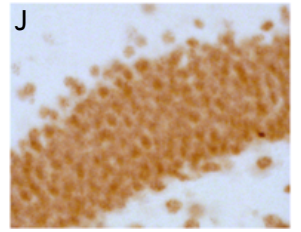

CA3
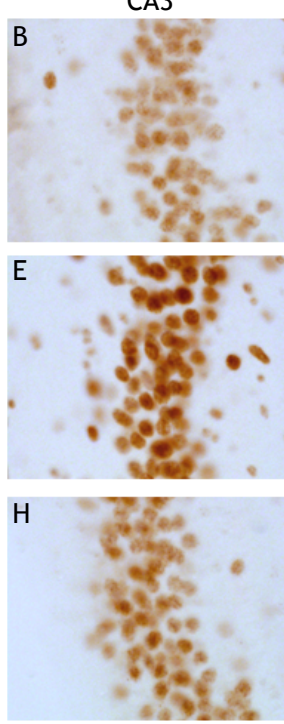

K

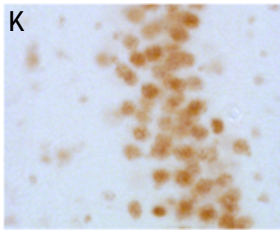

CA1-2
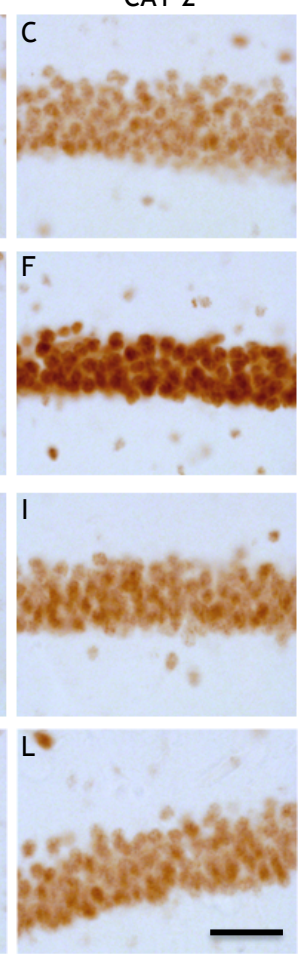

Figure 3. Representative photomicrographs of 5-hydroxymethylcytosine (5-hmC) immunoreactivity (IR). High magnification representative photomicrographs of the hippocampal dentate gyrus (DG), cornu ammonis (CA) 3 , and CA1-2 regions are shown. A-C represent a 3-month-old wild-type (WT) mouse, D- F represent a 9-month-old WT mouse. G-I, represent a 3-month-old APPswe/PS1 $\triangle E 9$ mouse, and J-L a 9-month-old APPswe/PS1 $\triangle E$ E9 mouse. Note that an increase in 5-hmC IR is observed from 3 to 9 months in WT mice, while no apparent age-related differences are observed in the APPswe/PS1 $\triangle E 9$ mice in all three hippocampal sub-regions. The images were taken with a $40 x$ objective. Scale bar $=50 \mu \mathrm{m}$.

mice $[38,44]$. Similar to the findings on $5-\mathrm{mC}$ IR in WT mice, 5-hmC IR in hippocampal subregions showed an age-related increase from 3- to 9-month-old in WT mice. 5-hmC has recently gained increased attention as it was described to be particularly abundant in the brain $[45,46]$. A number of studies have shown that $5-\mathrm{hmC}$, which is an oxidized form of 5-mC, has a different role in the regulation of gene expression when compared to 5-mC [47-50]. Our finding of an age-associated increase of 5-hmC IR in WT mice parallels a report showing increases in $5-\mathrm{hmC}$ in the aging mouse cerebellum [22]. Interestingly, the increases in DNA hydroxymethylation in that study were particularly pronounced in genes related to neurodegeneration, including those encoding presenilins and secretases. The current findings are also in agreement with our previous observations of increasing hippocampal 5-hmC IR with age in mice [30]. We have furthermore observed correlations between $5-\mathrm{mC}$ and 5-hmC in WT mice, but considering the significant main effects of age, it is difficult to ascertain whether the correlations observed in these cases are independent of age.

\subsection{Disturbed age-related alterations of 5-mC and 5-hmC in APPswe/PS1 $\triangle \mathrm{E} 9$ mice}

Noticeable differences were observed in the temporal patterns of age-related changes in $5-\mathrm{mC}$ IR in WT as compared with APPswe/ PS1 $1 \mathrm{E} 9$ mice: $5-\mathrm{mC}$ IR increased with aging from 3 to 9 months of age in WT mice, while aging from 3 to 9 months of age in APPswe/ PS1 $\triangle E 9$ mice was associated with lower levels of 5-mC IR. A similar, but less pronounced, 
DG

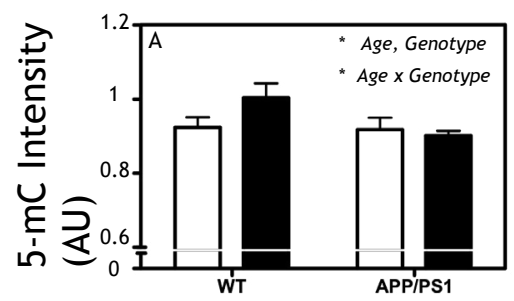

$\underbrace{20}$

ֻั
CA3

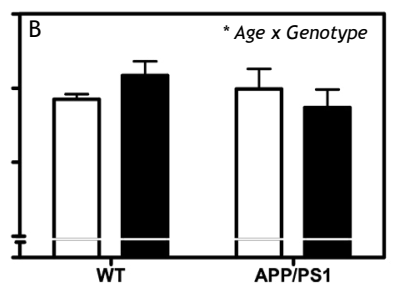

CA1-2

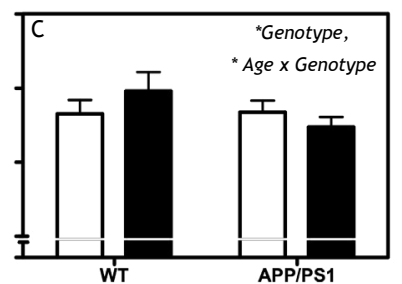

A1-2

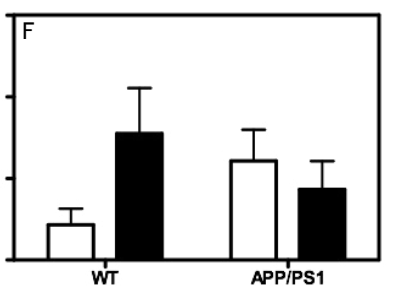

Figure 4. 5-methylcytosine (5-mC) intensity and surface area. Mean and standard error of the mean intensity value measurements of 5-mC immunoreactivity (IR; A-F). Pooled data from the 4 groups of 3-month-old (white bars) and 9-month-old wild-type (WT) and APPswe/PS1 $\triangle$ E9 mice (black bars) are represented separately for the dentate gyrus (DG; $A, D)$, cornu ammonis (CA) $3(B, E)$, and CA1-2 (C, F). Statistically significant effects from the univariate analysis of variance including age and genotype are displayed in the upper right corner of the graphs. In case of a significant age $x$ genotype interaction no main effects are shown. Statistically significant differences between the age and genotype groups, as determined through Bonferroni-corrected post-hoc comparisons, are also indicated in the graphs. AU, arbitrary units; $\mathrm{p}<0.05 ;{ }^{* *} \mathrm{p}<0.01$; *** $\mathrm{p}<0.001$.

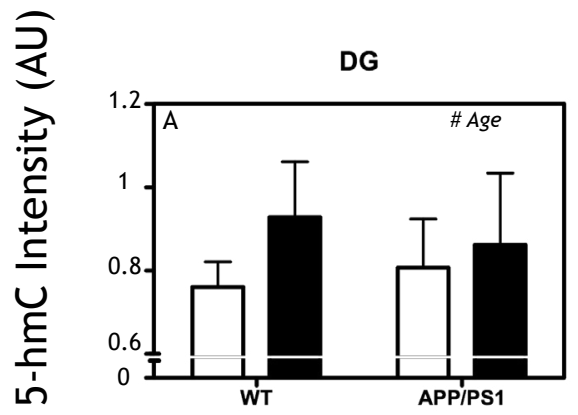

CA3

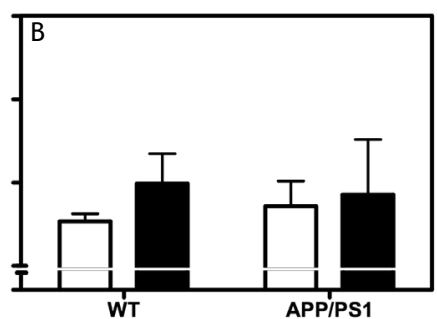

CA3

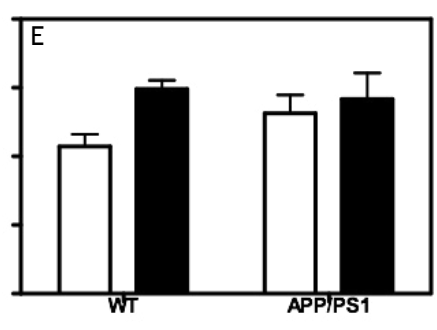

CA1-2

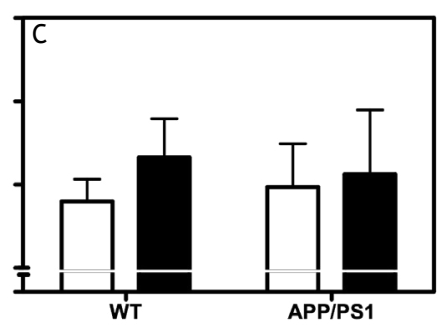

CA1-2

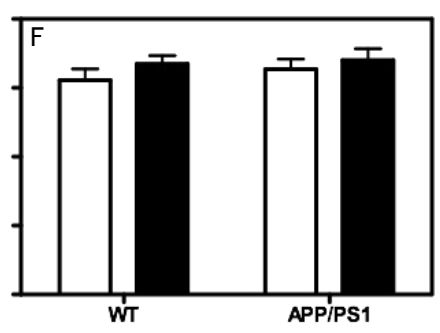

Figure 5. 5-hydroxymethylcytosine (5-hmC) intensity and surface area. Mean and standard error of the mean intensity value measurements of 5-hmC immunoreactivity (IR; A-F). Pooled data from the 4 groups of 3-month-old (white bars) and 9-month-old (black bars) wild-type (WT) and APPswe/PS1 $\triangle$ E9 mice are represented separately for the dentate gyrus (DG; A, D), cornu ammonis (CA) 3 (B, E), and CA1-2 (C, F). No statistically significant effects of age or genotype were found with a univariate analysis of variance, however a stratified analysis per genotype showed age-related increases of 5 -hmC intensity in the WT mice, as shown in the graphs. AU, arbitrary units; ${ }^{*} \mathrm{p}<0.05$. 

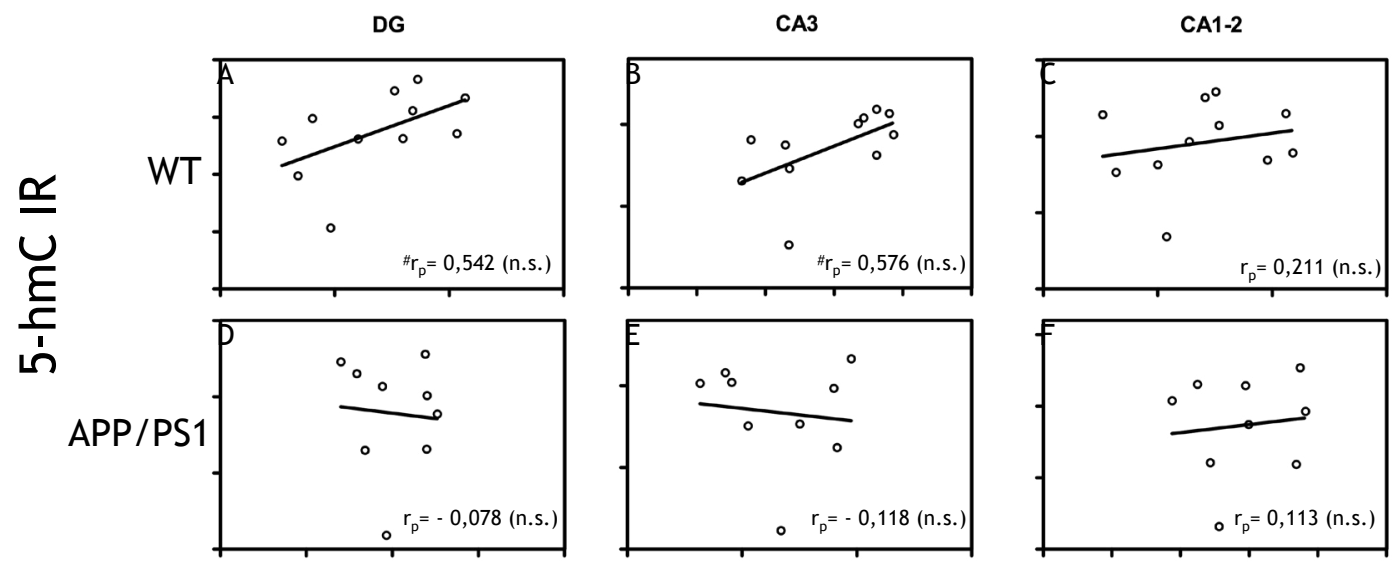

\section{$5-\mathrm{mC} I \mathrm{R}$}

Figure 6. 5-hydroxymethylcytosine (5-hmC) and 5-methylcytosine (5-mC) correlation analysis. Correlation analysis of 5-hmC and 5-mC immunoreactivity (IR) for wild-type (WT; A-C) and APPswe/PS1 $\triangle E$ E (D-F) mice are represented separately for the dentate gyrus (DG; A, D), cornu ammonis (CA) 3 (B, E) and CA1-2 (C, F). Spearman's correlation coefficients (rp) are noted in the bottom right of each graph. $n s$, non-significant $(p>0.05)$.

opposition of age-related patterns was found for 5-hmC IR in the hippocampus: 5-hmC IR increased with aging from 3 to 9 months of age in WT mice, but did not show significant agerelated changes in APPswe/PS1 $\triangle \mathrm{E} 9$ mice. Thus, our findings indicate that mutant APP and/or PS1 induce alterations in the molecular cascade of DNA methylation and hydroxymethylation during aging in the mouse hippocampus, and suggest that aberrant amyloid processing may be associated with DNA (hydroxy)methylation changes also observed in the human AD brain [25,51].

The age-related disturbances in 5-mC and 5 -hmC in the APPswe/PS1 $\triangle \mathrm{E} 9$ from 3 to 9 months of age coincide with the development of AD-like pathology and behavioral deficits in this model [52-54]. Although our findings indicate that mutant APP and/or PS1 impact on age-related changes of DNA methylation and hydroxymethylation, it remains to be answered whether age-related changes of DNA methylation and hydroxymethylation are primarily causal or compensatory in the development of AD-associated pathology [21]. In this context, other studies have documented that intervening in the DNA methylation processes has consequences on amyloid processing. For example, dietary disturbances of the one-carbon metabolism, which regulates the methylation potential, induced promoter hypomethylation of the PS1 gene and increased amyloid plaque deposition in mice $[11,55,56]$, while dietary supplementation with the methyl-donor S-adenosylmethionine was found to ameliorate these alterations [57].

$A$ recent study on epigenetic changes with age in various animal models of $A D$ did not find an age-related decrease in hippocampal 5 -mC or 5-hmC in APP/PS1dE9 mice, but did find an age-related decrease in hippocampal 5 -mC in $\mathrm{J} 20$ mice, expressing human mutant APP [58]. An important distinction with the present study, however, is that we compared 5-mC and 5-hmC levels before and after plaque development, while the youngest APP/PS1dE9 mice included in the study by Lardenoije et al. were 6 months of age, which coincides with the first appearance of plaques. It could thus be said that while the present study detects epigenetic changes after plaque deposition, the study by Lardenoije et al. would detect age-related epigenetic changes under the increasing presence of plaques. Given their observation of no further age-related increase in 5-mC and 5-hmC in APP/PS1dE9, it is possible that, in these mice, levels of the epigenetic markers drop quickly after the first plaque deposition, but do not significantly drop during further aging. Potentially, the agerelated increases in 5-mC and 5-hmC observed in WT mice and the decreases in these markers in relation to the development of AD pathology are independent, and cancel each other out at advanced ages when looking at global levels of these markers. Indeed, when comparing the three $A D$ mouse models included in the Lardenoije et al. study, the model with the least amount of plaque deposition, the 3xTg$A D$ model, shows age-related increases in hippocampal DNA methylation (age-related epigenetic processes mainly drive global changes), the model with intermediate plaque deposition, the APP/PS1dE9 model, shows no significant age-related changes (age- and AD-related epigenetic processes equally drive global changes), and the model with the most severe plaque load, the J20 model, shows age-related decreases (AD-related epigenetic processes mainly drive global changes).

Compared to our findings, Cadena-delCastillo et al. [59] have found an age-dependent decline in global 5-mC and an age-dependent increase in global 5 -hmC in the cortex of 
3xTg-AD mice, which carry mutations of APP, PS1, and Tau [60]. This discrepancy could be explained by methodological differences, such as the different brain areas examined (hippocampus vs. cortex), tissue processing or alternatively directly linked to the differences in the mutations and neuropathology characteristics between the 3xTg-AD and the APP/PS1 $\triangle E 9$ mice $[61,62]$. More specifically the $3 x \operatorname{Tg}-A D$ mice develop tau pathology in addition to amyloid pathology. Therefore, it could be speculated that the presence of tau pathology induces alterations in $5-\mathrm{hmC}$ that were not captured in our study. To support this notion studies in $A D$ patients and transgenic AD drosophila have specifically linked 5 -hmC changes with tau-mediated neurotoxicity [63]. Clearly, the interrelations between aging, amyloid processing, and DNA (hydroxy) methylation are complex and further work in this area is needed.

Overall, the present findings can be linked to our previous observations of decreased 5-mC and 5-hmC in the hippocampus of AD patients and controls [25] and suggest that the presence of amyloid pathology is closely related to robust changes in global DNA methylation. In line with our present findings, various reports have shown alterations in DNA methylation in certain brain regions as well as in lymphocytes of $A D$ patients when compared to controls (for review see: [5]). For example, Mastroeni and colleagues [6] have shown a robust loss of 5-mC IR and DNA methylation-stabilizing factors, like Dnmt1, Methyl-CpG Binding Protein (MeCP) 2 and HDAC2 in the entorhinal cortex of AD patients when compared to controls, and in a monozygotic twin pair discordant for $A D$ [64]. Studies focusing on methylation changes in specific genes, repetitive elements and ribosomal DNA have furthermore reported significant changes in $A D$ cases as compared to controls $[7,13,14,65-68]$.
It is important to mention that many of the current techniques used for the detection of DNA methylation either cannot detect 5-hmC or cannot discriminate it reliably from $5-\mathrm{mC}$ [69-71]. Thus, the importance of 5-hmC might be underestimated in current epigenetics research on aging and AD [33]. Interestingly our group has shown an increase of 5 -hmC in a specific layer of the sub-ventricular zone of patients with $A D$ which is associated with neurogenesis and proliferation in that area [39].

\subsection{Limitations, future prospects and conclusions}

The current study design involved WT and double transgenic APPswe/PS1 $\triangle E 9$ mice. As such, it cannot be explained whether the findings of this study are due to genetic variation in the APP gene, the PS1 gene or the combination of both. While the observed epigenetic changes might be associated with the presence of $A D$ pathology in the transgenic mice and the stochastic events that occur with aging, it should be noted that epigenetic mechanisms are dynamic processes that are subject to environmental exposures and thus the effects of the environment and its impact on the epigenome should be more thoroughly investigated in the context of $A D$.

While the present study focused solely on the hippocampus of male mice, investigation of potential sex effects and examination of other brain regions that are either heavily affected by aging and $A D$ or are resilient are of equally high importance. The fact that 5-mC but not 5 -hmC decreases in correspondence with $A \beta$ plaque deposition in these mice suggests that mutant APP and/or PS1 disturb the balance between these epigenetic regulators during aging. Clearly, the exact implications of this disturbance and its possible role in the pathophysiology of AD remain to be elucidated. The current immunohistochemical approach allows for the detection of hippocampal subregion-specific changes and gives an estimate of total levels of 5-mC and 5-hmC. It would be interesting to investigate gene-specific alterations of the two epigenetic markers and identify potential target pathways that are specifically affected by aging and by APP and PS1. Evidence from AD case-control postmortem studies employing a genome wide approach points towards a widespread ADassociated dysregulation of the DNA methylome and have identified novel targets and pathways that maybe involved in the pathophysiology of $A D[13,14]$, however, apart from a recent report on the DNA hydroxymethylation profile of $A D$ [26] little is known with regards to the involvement of gene-specific 5-hmC changes in AD. Evidently, the appropriate methods for the precise detection of each modification should be selected. Furthermore, the functional impact of epigenetic changes in DNA (hydroxy) methylation on gene expression, associated AD-like pathology, and behavioral correlates should be further examined.

In conclusion, the present findings reveal differential age-associated changes of DNA methylation and hydroxymethylation in the hippocampus of WT and transgenic APPswe/ $\mathrm{PS} 1 \triangle \mathrm{E} 9$ mice and suggest that an altered DNA methylation/hydroxymethylation balance is involved in the pathophysiology of $A D$.

\section{Acknowledgements}

Funding: This work was supported by the Internationale Stichting Alzheimer Onderzoek [grant numbers 07551, 11532, 09552]; the Netherlands Organization for Scientific Research [grant numbers 916.11.086, 022.005.019]; the European Commission [grant number MC-EST 020589]; and the National Institutes of Health [grant number P50 AG05138]. The authors declare no conflicts of interest. 
[1] W.S. Liang, T. Dunckley, T.G. Beach, A. Grover, D. Mastroeni, K. Ramsey, R.J. Caselli, W.A. Kukull, D. McKeel, J.C. Morris, C.M. Hulette, D. Schmechel, E.M. Reiman, J. Rogers, D.A. Stephan, Neuronal gene expression in non-demented individuals with intermediate Alzheimer's Disease neuropathology, Neurobiol. Aging. 31 (2010) 549-566. doi:10.1016/j.neurobiolaging.2008.05.013.

[2] T. Dunckley, T.G. Beach, K.E. Ramsey, A. Grover, D. Mastroeni, D.G. Walker, B.J. LaFleur, K.D. Coon, K.M. Brown, R. Caselli, W. Kukull, R. Higdon, D. McKeel, J.C. Morris, C. Hulette, D. Schmechel, E.M. Reiman, J. Rogers, D.A. Stephan, Gene expression correlates of neurofibrillary tangles in Alzheimer's disease, Neurobiol. Aging. 27 (2006) 13591371. doi:10.1016/j.neurobiolaging.2005.08.013.

[3] J. Hardy, The amyloid hypothesis for Alzheimer's disease: a critical reappraisal, J. Neurochem. 110 (2009) 1129-1134. doi:10.1111/ j.1471-4159.2009.06181.x.

[4] R.E. Tanzi, L. Bertram, Twenty Years of the Alzheimer's Disease Amyloid Hypothesis: A Genetic Perspective, Cell. 120 (2005) 545-555. doi:10.1016/j.cell.2005.02.008.

[5] R. Lardenoije, A. latrou, G. Kenis, K. Kompotis, H.W. Steinbusch, D. Mastroeni, P. Coleman, C.A. Lemere, P.R. Hof, D.L. van den Hove, B.P. Rutten, The epigenetics of aging and neurodegeneration, Prog Neurobiol. 131 (2015) 21-64. doi:10.1016/j.pneurobio.2015.05.002.

[6] D. Mastroeni, A. Grover, E. Delvaux, C. Whiteside, P.D. Coleman, J. Rogers, Epigenetic mechanisms in Alzheimer's disease, 2011. doi:10.1016/j.neurobiolaging.2010.08.017.

[7] V. Bollati, D. Galimberti, L. Pergoli, E. Dalla Valle, F. Barretta, F. Cortini, E. Scarpini, P.A. Bertazzi, A. Baccarelli, DNA methylation in repetitive elements and Alzheimer disease, Brain. Behav. Immun. 25 (2011) 1078-1083. doi:10.1016/j.bbi.2011.01.017.

[8] K.-L. Chen, S.S.-S. Wang, Y.-Y. Yang, R.-Y. Yuan, R.-M. Chen, C.-J. Hu, The epigenetic effects of amyloid- $\beta 1-40$ on global DNA and neprilysin genes in murine cerebral endothelial cells, Biochem. Biophys. Res. Commun. 378 (2009) 57-61. doi:10.1016/j.bbrc.2008.10.173.

[9] L. Cong, J. Jia, W. Qin, Y. Ren, Y. Sun, Genome-wide analysis of DNA methylation in an APP/PS1 mouse model of Alzheimer's disease., Acta Neurol. Belg. 114 (2014) 195-206. doi:10.1007/s13760-0130267-6.

[10] K. Coupland, W.S. Kim, G. Halliday, C. Dobson-Stone, J.B.J. Kwok, MAPT methylation in Alzheimer's disease, Alzheimer's Dement. 10 (2014) P317-P318. doi:10.1016/j.jalz.2014.05.274.

[11] A. Fuso, V. Nicolia, A. Pasqualato, M.T. Fiorenza, R.A. Cavallaro, S. Scarpa, Changes in Presenilin 1 gene methylation pattern in dietinduced B vitamin deficiency, Neurobiol. Aging. 32 (2011) 187-199. doi:10.1016/j.neurobiolaging.2009.02.013.

[12] J. V. Sanchez-Mut, E. Aso, N. Panayotis, I. Lott, M. Dierssen, A. Rabano, R.G. Urdinguio, A.F. Fernandez, A. Astudillo, J.I. Martin-Subero, B. Balint, M.F. Fraga, A. Gomez, C. Gurnot, J.-C. Roux, J. Avila, T.K. Hensch, I. Ferrer, M. Esteller, DNA methylation map of mouse and human brain identifies target genes in Alzheimer's disease, Brain. 136 (2013)
3018-3027. doi:10.1093/brain/awt237.

[13] P.L. De Jager, G. Srivastava, K. Lunnon, J. Burgess, L.C. Schalkwyk, L. Yu, M.L. Eaton, B.T. Keenan, J. Ernst, C. McCabe, A. Tang, T. Raj, J. Replogle, W. Brodeur, S. Gabriel, H.S. Chai, C. Younkin, S.G. Younkin, F. Zou, M. Szyf, C.B. Epstein, J.A. Schneider, B.E. Bernstein, A. Meissner, N. ErtekinTaner, L.B. Chibnik, M. Kellis, J. Mill, D.A. Bennett, Alzheimer's disease: early alterations in brain DNA methylation at ANK1, BIN1, RHBDF2 and other loci, Nat. Neurosci. 17 (2014) 1156-1163. doi:10.1038/ nn.3786.

[14] K. Lunnon, R. Smith, E. Hannon, P.L. De Jager, G. Srivastava, M. Volta, C. Troakes, S. Al-Sarraj, J. Burrage, R. Macdonald, D. Condliffe, L.W. Harries, P. Katsel, V. Haroutunian, Z. Kaminsky, C. Joachim, J. Powell, S. Lovestone, D.A. Bennett, L.C. Schalkwyk, J. Mill, Methylomic profiling implicates cortical deregulation of ANK1 in Alzheimer's disease, Nat. Neurosci. 17 (2014) 1164-1170. doi:10.1038/nn.3782.

[15] M. Kilgore, C.A. Miller, D.M. Fass, K.M. Hennig, S.J. Haggarty, J.D. Sweatt, G. Rumbaugh, Inhibitors of class 1 histone deacetylases reverse contextual memory deficits in a mouse model of Alzheimer's disease., Neuropsychopharmacology. 35 (2010) 870-80. doi:10.1038/ npp.2009.197.

[16] Z. Wang, X.-J. Zhang, T. Li, J. Li, Y. Tang, W. Le, Valproic acid reduces neuritic plaque formation and improves learning deficits in $\operatorname{APP}(S w e)$ /PS1(A246E) transgenic mice via preventing the prenatal hypoxiainduced down-regulation of neprilysin., CNS Neurosci. Ther. 20 (2014) 209-17. doi:10.1111/cns.12186.

[17] S. Kriaucionis, N. Heintz, The nuclear DNA base 5-hydroxymethylcytosine is present in Purkinje neurons and the brain., Science (80-. ). 324 (2009) 929-30. doi:10.1126/ science.1169786.

[18] M. Tahiliani, K.P. Koh, Y. Shen, W.A. Pastor, H. Bandukwala, Y. Brudno, S. Agarwal, L.M. Iyer, D.R. Liu, L. Aravind, A. Rao, Conversion of 5-Methylcytosine to 5-Hydroxymethylcytosine in Mammalian DNA by MLL Partner TET1, Science (80-. ). 324 (2009) 930-935. doi:10.1126/ science.1170116.

[19] D.P. Gavin, K.A. Chase, R.P. Sharma, Active DNA demethylation in post-mitotic neurons: A reason for optimism, Neuropharmacology. 75 (2013) 233-245. doi:10.1016/j.neuropharm.2013.07.036.

[20] J.U. Guo, Y. Su, C. Zhong, G. Ming, H. Song, Hydroxylation of 5-Methylcytosine by TET1 Promotes Active DNA Demethylation in the Adult Brain, Cell. 145 (2011) 423-434. doi:10.1016/j.cell.2011.03.022.

[21] D. LA van den Hove, G. Kenis, B.P. Rutten, Epigenetic dysregulation in Alzheimer's disease: cause or consequence?, Epigenomics. 6 (2014) 9-11. doi:10.2217/epi.13.84.

[22] K.E. Szulwach, X. Li, Y. Li, C.-X. Song, H. Wu, Q. Dai, H. Irier, A.K. Upadhyay, M. Gearing, A.I. Levey, A. Vasanthakumar, L.A. Godley, Q. Chang, X. Cheng, C. He, P. Jin, 5-hmC-mediated epigenetic dynamics during postnatal neurodevelopment and aging, Nat. Neurosci. 14 (2011) 1607-1616. doi:10.1038/nn.2959.

[23] C.-X. Song, K.E. Szulwach, Y. Fu, Q. Dai, C. Yi, X. Li, Y. Li, C.-H. Chen, W. 
Zhang, X. Jian, J. Wang, L. Zhang, T.J. Looney, B. Zhang, L.A. Godley, L.M. Hicks, B.T. Lahn, P. Jin, C. He, Selective chemical labeling reveals the genome-wide distribution of 5-hydroxymethylcytosine, Nat. Biotechnol. 29 (2011) 68-72. doi:10.1038/nbt.1732.

[24] A.R. Morgan, G. Hamilton, D. Turic, L. Jehu, D. Harold, R. Abraham, P. Hollingworth, V. Moskvina, C. Brayne, D.C. Rubinsztein, A. Lynch, B. Lawlor, M. Gill, M. O'Donovan, J. Powell, S. Lovestone, J. Williams, M.J. Owen, Association analysis of 528 intra-genic SNPs in a region of chromosome 10 linked to late onset Alzheimer's disease, Am. J. Med. Genet. Part B Neuropsychiatr. Genet. 147B (2008) 727-731. doi:10.1002/ajmg.b.30670.

[25] L. Chouliaras, D. Mastroeni, E. Delvaux, A. Grover, G. Kenis, P.R.P.R. Hof, H.W.M.H.W.M. Steinbusch, P.D.P.D. Coleman, B.P.F.B.P.F. Rutten, D.L.A.D.L.A. van den Hove, Consistent decrease in global DNA methylation and hydroxymethylation in the hippocampus of Alzheimer's disease patients, Neurobiol. Aging. 34 (2013) 2091-2099. doi:10.1016/j.neurobiolaging.2013.02.021.

[26] J. Zhao, Y. Zhu, J. Yang, L. Li, H. Wu, P.L. De Jager, P. Jin, D.A. Bennett, A genome-wide profiling of brain DNA hydroxymethylation in Alzheimer's disease, Alzheimer's Dement. (2017). doi:10.1016/j. jalz.2016.10.004.

[27] D.G. Hernandez, M.A. Nalls, J.R. Gibbs, S. Arepalli, M. van der Brug, S. Chong, M. Moore, D.L. Longo, M.R. Cookson, B.J. Traynor, A.B. Singleton, Distinct DNA methylation changes highly correlated with chronological age in the human brain, Hum. Mol. Genet. 20 (2011) 1164-1172. doi:10.1093/hmg/ddq561.

[28] L. Chouliaras, B.P.F.B.P.F.B.P.F. Rutten, G. Kenis, O. Peerbooms, P.J.P.J. Visser, F. Verhey, J. van Os, H.W.M.H.W.M.M. Steinbusch, D.L. a. D.L.A.D.L. a van den Hove, Epigenetic regulation in the pathophysiology of Alzheimer's disease, Prog. Neurobiol. 90 (2010) 498-510. doi:10.1016/j.pneurobio.2010.01.002.

[29] A. latrou, G. Kenis, B.P.F.F. Rutten, K. Lunnon, D.L.A.A. van den Hove, Epigenetic dysregulation of brainstem nuclei in the pathogenesis of Alzheimer's disease: looking in the correct place at the right time?, 2017. doi:10.1007/s00018-016-2361-4.

[30] L. Chouliaras, D.L.A. van den Hove, G. Kenis, S. Keitel, P.R. Hof, J. van Os, H.W.M. Steinbusch, C. Schmitz, B.P.F. Rutten, Age-related increase in levels of 5-hydroxymethylcytosine in mouse hippocampus is prevented by caloric restriction., Curr. Alzheimer Res. 9 (2012) 53644.

[31] L. Chouliaras, D.L.A. van den Hove, G. Kenis, S. Keitel, P.R. Hof, J. van Os, H.W.M. Steinbusch, C. Schmitz, B.P.F. Rutten, Prevention of age-related changes in hippocampal levels of 5-methylcytidine by caloric restriction, Neurobiol. Aging. (2012). doi:10.1016/j. neurobiolaging.2011.06.003.

[32] R. Lardenoije, D.A. van den Hove, T.S.J. Vaessen, A. latrou, K.P. V Meuwissen, B.T.J. van Hagen, G. Kenis, H.W.M. Steinbusch, C. Schmitz, B.P.F. Rutten, Epigenetic modifications in mouse cerebellar Purkinje cells: effects of aging, caloric restriction, and overexpression of superoxide dismutase 1 on 5-methylcytosine and 5-hydroxymethylcytosine., Neurobiol. Aging. 36 (2015) 3079-3089. doi:10.1016/j.neurobiolaging.2015.08.001.

[33] van den Hove DL, Chouliaras L, Rutten BPF, Hove DLA Van Den. The role of 5-hydroxymethylcytosine in aging and Alzheimer's disease: current status and prospects for future studies. Curr Alzheimer Res. 2012;

[34] H. Sasaguri, P. Nilsson, S. Hashimoto, K. Nagata, T. Saito, B. De Strooper, J. Hardy, R. Vassar, B. Winblad, T.C. Saido, APP mouse models for Alzheimer's disease preclinical studies, EMBO J. (2017). doi:10.15252/ embj.201797397.

[35] J.L. Jankowsky, H.H. Slunt, T. Ratovitski, N.A. Jenkins, N.G. Copeland, D.R. Borchelt, Co-expression of multiple transgenes in mouse CNS: a comparison of strategies, Biomol. Eng. 17 (2001) 157-165. doi:10.1016/S1389-0344(01)00067-3.

[36] P. van Tijn, F.J.A. Dennissen, R.J.G. Gentier, B. Hobo, D. Hermes, H.W.M. Steinbusch, F.W. Van Leeuwen, D.F. Fischer, Mutant ubiquitin decreases amyloid $\beta$ plaque formation in a transgenic mouse model of Alzheimer's disease, Neurochem. Int. 61 (2012) 739-748. doi:10.1016/j.neuint.2012.07.007.

[37] J.L. Jankowsky, D.J. Fadale, J. Anderson, G.M. Xu, V. Gonzales, N.A. Jenkins, N.G. Copeland, M.K. Lee, L.H. Younkin, S.L. Wagner, S.G. Younkin, D.R. Borchelt, Mutant presenilins specifically elevate the levels of the 42 residue $\beta$-amyloid peptide in vivo: Evidence for augmentation of a 42-specific $\gamma$ secretase, Hum. Mol. Genet. 13 (2004) 159-170. doi:10.1093/hmg/ddh019.

[38] L. Chouliaras, D.L.A. van den Hove, G. Kenis, J. Dela Cruz, M.A.M. Lemmens, J. van Os, H.W.M. Steinbusch, C. Schmitz, B.P.F. Rutten, Caloric restriction attenuates age-related changes of DNA methyltransferase 3a in mouse hippocampus, Brain. Behav. Immun. 25 (2011) 616-623. doi:10.1016/j.bbi.2010.11.016.

[39] D. Mastroeni, L. Chouliaras, D.L.D.L. Van den Hove, J. Nolz, B.P.F.B.P.F. Rutten, E. Delvaux, P.D.P.D. Coleman, Increased 5-hydroxymethylation levels in the sub ventricular zone of the Alzheimer's brain, Neuroepigenetics. 6 (2016) 26-31. doi:10.1016/j.nepig.2016.04.002.

[40] P.C. Rath, M.S. Kanungo, Methylation of repetitive DNA sequences in the brain during aging of the rat, FEBS Lett. 244 (1989) 193-198. doi:10.1016/0014-5793(89)81191-3.

[41] S.H. Ryu, K. Kang, T. Yoo, C.O. Joe, J.H. Chung, Transcriptional repression of repeat-derived transcripts correlates with histone hypoacetylation at repetitive DNA elements in aged mice brain, Exp. Gerontol. 46 (2011) 811-818. doi:10.1016/j.exger.2011.07.001.

[42] B.C. Christensen, E.A. Houseman, C.J. Marsit, S. Zheng, M.R. Wrensch, J.L. Wiemels, H.H. Nelson, M.R. Karagas, J.F. Padbury, R. Bueno, D.J. Sugarbaker, R.-F. Yeh, J.K. Wiencke, K.T. Kelsey, Aging and Environmental Exposures Alter Tissue-Specific DNA Methylation Dependent upon CpG Island Context, PLoS Genet. 5 (2009) e1000602. doi:10.1371/journal.pgen.1000602.

[43] K.D. Siegmund, C.M. Connor, M. Campan, T.I. Long, D.J. Weisenberger, D. Biniszkiewicz, R. Jaenisch, P.W. Laird, S. Akbarian, DNA Methylation in the Human Cerebral Cortex Is Dynamically Regulated throughout the Life Span and Involves Differentiated Neurons, PLoS One. 2 (2007) e895. doi:10.1371/journal.pone.0000895. 
[44] L. Chouliaras, D.L.A. van den Hove, G. Kenis, M. van Draanen, P.R. Hof, J. van Os, H.W.M. Steinbusch, C. Schmitz, B.P.F. Rutten, Histone deacetylase 2 in the mouse hippocampus: attenuation of age-related increase by caloric restriction., Curr. Alzheimer Res. 10 (2013) 868-76. doi:10.2174/1567205011310080009.

[45] Lunnon K, Hannon E, Smith RG, Dempster E, Wong C, Burrage J, Troakes C, Al-Sarraj S, Kepa A, Schalkwyk L, Mill J. Variation in 5-hydroxymethylcytosine across human cortex and cerebellum, Genome Biol. 17 (2016) 27. doi:10.1186/s13059-016-0871-x.

[46] M. Münzel, D. Globisch, T. Brückl, M. Wagner, V. Welzmiller, S. Michalakis, M. Müller, M. Biel, T. Carell, Quantification of the Sixth DNA Base Hydroxymethylcytosine in the Brain, Angew. Chemie Int. Ed. 49 (2010) 5375-5377. doi:10.1002/anie.201002033.

[47] S. Ito, A.C. D’Alessio, O. V. Taranova, K. Hong, L.C. Sowers, Y. Zhang, Role of Tet proteins in $5 \mathrm{mC}$ to $5 \mathrm{hmC}$ conversion, ES-cell self-renewal and inner cell mass specification, Nature. 466 (2010) 1129-1133. doi:10.1038/nature09303.

[48] V.Valinluck, L.C. Sowers, Endogenous Cytosine Damage Products Alter the Site Selectivity of Human DNA Maintenance Methyltransferase DNMT1, Cancer Res. 67 (2007) 946-950. doi:10.1158/0008-5472.CAN06-3123.

[49] V. Valinluck, H.-H. Tsai, D.K. Rogstad, A. Burdzy, A. Bird, L.C. Sowers, Oxidative damage to methyl-CpG sequences inhibits the binding of the methyl-CpG binding domain (MBD) of methyl-CpG binding protein 2 (MeCP2), Nucleic Acids Res. 32 (2004) 4100-4108. doi:10.1093/nar/gkh739.

[50] S.-G. Jin, X. Wu, A.X. Li, G.P. Pfeifer, Genomic mapping of 5-hydroxymethylcytosine in the human brain, Nucleic Acids Res. 39 (2011) 5015-5024. doi:10.1093/nar/gkr120.

[51] D. Condliffe, A. Wong, C. Troakes, P. Proitsi, Y. Patel, L. Chouliaras, C. Fernandes, J. Cooper, S. Lovestone, L. Schalkwyk, J. Mill, K. Lunnon, Cross-region reduction in 5-hydroxymethylcytosine in Alzheimer's disease brain, Neurobiol. Aging. 35 (2014) 1850-1854. doi:10.1016/j. neurobiolaging.2014.02.002.

[52] M. Garcia-Alloza, E.M. Robbins, S.X. Zhang-Nunes, S.M. Purcell, R.A. Betensky, S. Raju, C. Prada, S.M. Greenberg, B.J. Bacskai, M.P. Frosch, Characterization of amyloid deposition in the APPswe/PS1dE9 mouse model of Alzheimer disease, Neurobiol. Dis. 24 (2006) 516524. doi:10.1016/j.nbd.2006.08.017.

[53] L. Ruan, Z. Kang, G. Pei, Y. Le, Amyloid deposition and inflammation in APPswe/PS1dE9 mouse model of Alzheimer's disease., Curr. Alzheimer Res. 6 (2009) 531-40.

[54] A. Savonenko, G.M. Xu, T. Melnikova, J.L. Morton, V. Gonzales, M.P.F. Wong, D.L. Price, F. Tang, A.L. Markowska, D.R. Borchelt, Episodic-like memory deficits in the APPswe/PS1dE9 mouse model of Alzheimer's disease: Relationships to $\beta$-amyloid deposition and neurotransmitter abnormalities, Neurobiol. Dis. 18 (2005) 602-617. doi:10.1016/j. nbd.2004.10.022.

[55] A. Fuso, V. Nicolia, R.A. Cavallaro, L. Ricceri, F. D'Anselmi, P. Coluccia, G. Calamandrei, S. Scarpa, B-vitamin deprivation induces hyperhomocysteinemia and brain S-adenosylhomocysteine, depletes brain S-adenosylmethionine, and enhances PS1 and BACE expression and amyloid- $\beta$ deposition in mice, Mol. Cell. Neurosci. 37 (2008) 731-746. doi:10.1016/j.mcn.2007.12.018.

[56] S. Scarpa, R.A. Cavallaro, F. D'Anselmi, A. Fuso, Gene silencing through methylation: an epigenetic intervention on Alzheimer disease., J. Alzheimers. Dis. 9 (2006) 407-14.

[57] A. Fuso, V. Nicolia, L. Ricceri, R.A. Cavallaro, E. Isopi, F. Mangia, M.T. Fiorenza, S. Scarpa, S-adenosylmethionine reduces the progress of the Alzheimer-like features induced by B-vitamin deficiency in mice, Neurobiol. Aging. 33 (2012) 1482.e1-1482.e16. doi:10.1016/j. neurobiolaging.2011.12.013.

[58] R. Lardenoije, D.L.A. van den Hove, M. Havermans, A. van Casteren, K.X. Le, R. Palmour, C.A. Lemere, B.P.F. Rutten, Age-related epigenetic changes in hippocampal subregions of four animal models of Alzheimer's disease, Mol. Cell. Neurosci. 86 (2018). doi:10.1016/j. mcn.2017.11.002.

[59] C. Cadena-del-Castillo, C. Valdes-Quezada, F. Carmona-Aldana, C. Arias, F. Bermúdez-Rattoni, F. Recillas-Targa, Age-dependent increment of hydroxymethylation in the brain cortex in the tripletransgenic mouse model of Alzheimer's disease., J. Alzheimers. Dis. 41 (2014) 845-54. doi:10.3233/JAD-132285.

[60] S. Oddo, A. Caccamo, J.D. Shepherd, M.P. Murphy, T.E. Golde, R. Kayed, R. Metherate, M.P. Mattson, Y. Akbari, F.M. LaFerla, Tripletransgenic model of Alzheimer's Disease with plaques and tangles: Intracellular $A \beta$ and synaptic dysfunction, Neuron. 39 (2003) 409421. doi:10.1016/S0896-6273(03)00434-3.

[61] S. Oddo, V. Vasilevko, A. Caccamo, M. Kitazawa, D.H. Cribbs, F.M. LaFerla, Reduction of soluble A?? and tau, but not soluble A?? alone, ameliorates cognitive decline in transgenic mice with plaques and tangles, J. Biol. Chem. 281 (2006) 39413-39423. doi:10.1074/jbc. M608485200.

[62] J.-E. Lee, P.-L. Han, An update of animal models of Alzheimer disease with a reevaluation of plaque depositions., Exp. Neurobiol. 22 (2013) 84-95. doi:10.5607/en.2013.22.2.84.

[63] A.I. Bernstein, Y. Lin, R.C. Street, L. Lin, Q. Dai, L. Yu, H. Bao, M. Gearing, J.J. Lah, P.T. Nelson, C. He, A.I. Levey, J.G. Mullé, R. Duan, P. Jin, 5-Hydroxymethylation-associated epigenetic modifiers of Alzheimer's disease modulate Tau-induced neurotoxicity, Hum. Mol. Genet. (2016) ddw109. doi:10.1093/hmg/ddw109.

[64] D. Mastroeni, A. McKee, A. Grover, J. Rogers, P.D. Coleman, Epigenetic Differences in Cortical Neurons from a Pair of Monozygotic Twins Discordant for Alzheimer's Disease, PLoS One. 4 (2009) e6617. doi:10.1371/journal.pone.0006617.

[65] R. Balazs, J. Vernon, J. Hardy, Epigenetic mechanisms in Alzheimer's disease: Progress but much to do, Neurobiol. Aging. 32 (2011) 11811187. doi:10.1016/j.neurobiolaging.2011.02.024.

[66] S.W. Bihaqi, H. Huang, J. Wu, N.H. Zawia, Infant exposure to lead (Pb) and epigenetic modifications in the aging primate brain: implications for Alzheimer's disease., J Alzheimers Dis. 27 (2011) 819-833.

[67]M. Pietrzak, G. Rempala, P.T. Nelson, J.-J. Zheng, M. Hetman, Epigenetic Silencing of Nucleolar rRNA Genes in Alzheimer's 
Disease, PLoS One. 6 (2011) e22585. doi:10.1371/journal. pone.0022585.

[68] J.Wu, M.R. Basha, B. Brock, D.P. Cox, F. Cardozo-Pelaez, C.A. McPherson, J. Harry, D.C. Rice, B. Maloney, D. Chen, D.K. Lahiri, N.H. Zawia, Alzheimer's Disease (AD)-Like Pathology in Aged Monkeys after Infantile Exposure to Environmental Metal Lead (Pb): Evidence for a Developmental Origin and Environmental Link for AD, J. Neurosci. 28 (2008).

[69]Y. Huang, W.A. Pastor, Y. Shen, M. Tahiliani, D.R. Liu, A. Rao, The Behaviour of 5-Hydroxymethylcytosine in Bisulfite Sequencing,
PLoS One. 5 (2010) e8888. doi:10.1371/journal.pone.0008888. [70] S.-G. Jin, S. Kadam, G.P. Pfeifer, Examination of the specificity of DNA methylation profiling techniques towards 5-methylcytosine and 5-hydroxymethylcytosine, Nucleic Acids Res. 38 (2010) e125-e125. doi:10.1093/nar/gkq223.

[71] C. Nestor, A. Ruzov, R. Meehan, D. Dunican, Enzymatic approaches and bisulfite sequencing cannot distinguish between 5-methylcytosine and 5-hydroxymethylcytosine in DNA, Biotechniques. 48 (2010) 317319. doi:10.2144/000113403. 
Total hippocampus

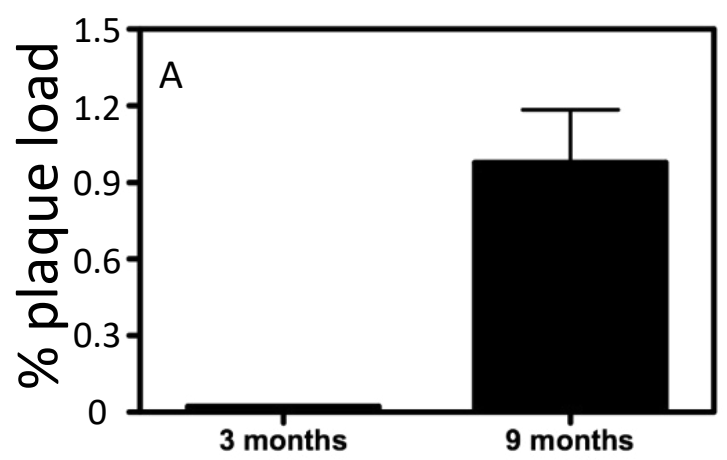

CA3

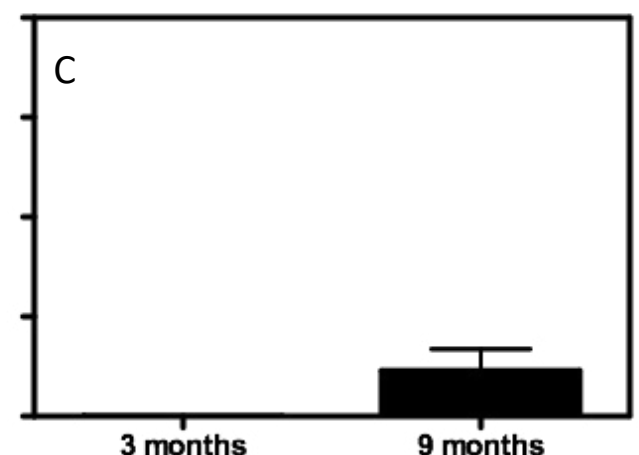

DG

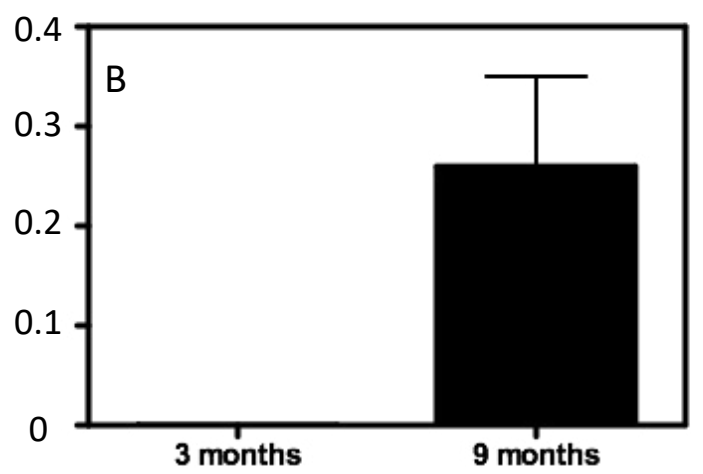

CA1-2

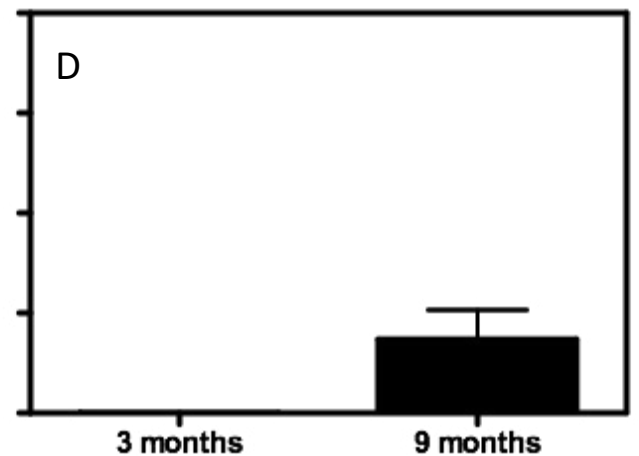

Supplementary Figure 1. Hippocampal plaque load in 3- and 9-month-old APPswe/PS1 $\triangle$ E9 mice. Mean and standard error of the mean of hippocampal plaque loads (percentage of area covered by plaques compared to total area) in the whole hippocampus (A) and the three hippocampal subregions (dentate gyrus [DG], cornu ammonis $[C A] 3$, and CA1-2; B, C, and D respectively) of transgenic APPswe/PS1 $\triangle E 9$ mice. Note that a clear increase in plaque load is observed from 3-to 9-month-old mice. These measurements were performed to validate the age-dependent hippocampal amyloid- $\beta$ plaque deposition in the mice used. 